\title{
Preparation of Magnesia Insulation Materials by Calcination of Walnut Shell Powder by Silica Sol Impregnation
}

\author{
Chi Kang, ${ }^{1}$ Guohua Li $\left(\mathbb{D},{ }^{1}\right.$ Jishuo Han, ${ }^{1}$ Shujiang Chen, ${ }^{1}$ Lin Tian, ${ }^{1}$ Xudong Luo, ${ }^{1}$ \\ and Lin Yuan ${ }^{2}$ \\ ${ }^{1}$ School of Materials and Metallurgy, University of Science and Technology Liaoning, Anshan 114051, China \\ ${ }^{2}$ Ruitai Materials Technology Co. Ltd., China Building Materials Academy, Beijing 100024, China \\ Correspondence should be addressed to Guohua Li; liguohuagui97@163.com
}

Received 23 November 2020; Revised 15 March 2021; Accepted 21 March 2021; Published 7 April 2021

Academic Editor: Matjaz Valant

Copyright (c) 2021 Chi Kang et al. This is an open access article distributed under the Creative Commons Attribution License, which permits unrestricted use, distribution, and reproduction in any medium, provided the original work is properly cited.

In this paper, magnesia porous aggregate was prepared by the foaming method with potassium oleate as the foaming agent. Secondly, the walnut shell powder was impregnated with the silica sol as the pore forming agent, and then, a new magnesia insulation material was prepared by $1300^{\circ} \mathrm{C}$ sintering. By changing the amount of the walnut shell powder added, the mechanical properties and thermal properties of the materials after sintering were studied. The results show that the sample with $10 \%$ walnut shell powder impregnated without the silica sol has a compression strength of $12 \mathrm{MPa}$. A sample with $10 \%$ walnut shell powder treated with the silica sol has a compression strength of $18 \mathrm{MPa}$. With the increase in the amount of the walnut shell powder added after impregnation, the bulk density, compression strength, and thermal conductivity of the sample all showed a decreasing trend, and the apparent porosity showed an increasing trend. When the additive amount is $20 \%$, the bulk density of the sample is $1.029 \mathrm{~g} /$ $\mathrm{cm}^{3}$, and the thermal conductivity is $0.382 \mathrm{~W} / \mathrm{m} \mathrm{K}\left(1050^{\circ} \mathrm{C}\right)$.

\section{Introduction}

Magnesia insulation materials have gained considerable attention and have been extensively applied in steel, cement, glass, and ceramic, owing to low thermal conductivity, high refractoriness, high porosity, and high thermal shock resistance [1-5]. At present, the preparation methods of insulation materials mainly include the direct foaming method [6], burn-out method [7], and sol-gel method [8]. The direct foaming method and burn-out method are widely used in the preparation of insulation materials due to the advantages of low price, large foam production, and controllable pores. Du et al. developed a high-porosity silicon nitride ceramic by the direct foaming method. Its porosity reached $92 \%-97 \%$, but its compression strength was only 0.85-5.38 MPa [9]; Zou et al. added nanometer aluminium oxide and zirconium oxide to prepare a nanoaperture magnesium oxide aggregate with a bulk density of $3.37 \mathrm{~g} /$ $\mathrm{cm}^{3}$ and a closed porosity of $4.3 \%$ [10]; Wu et al. used magnesia lightweight aggregate to produce insulation materials, and the apparent porosity of the sample was $27.8 \%$ after sintering, and the compression strength was $68.4 \mathrm{MPa}$ [11]; Obada et al. prepared a ceramic membrane with enlarged pore by using ceramic clay and foaming agent PHDPE and found that the porosity reached $62 \%$ and the compression strength did not exceed $18 \mathrm{MPa}$ [12].

The pore structure and the distribution in the material will directly affect the performance of the material. Although the direct foaming method and the burn-out method can produce pores, the pore shape and size are difficult to control, resulting in a decrease in the mechanical properties of the material so that it cannot meet the requirements $[13,14]$. At present, the use of the sol as a pretreatment fluid or sintering accelerator in the preparation of porous materials to improve the internal pore structure of the material has attracted widespread attention from scholars at home and abroad. Wei et al. prepared porous alumina ceramics by impregnating rice husks with the zirconia sol. Compared with the sample prepared without any impregnated rice husk, the internal pore shape of the sample has changed 
significantly, and its intensity has been significantly improved [15]; Yang et al. added the zirconia sol as an inorganic bond to prepare the mullite fiber ceramics, whose bulk density is $0.45-0.66 \mathrm{~g} / \mathrm{cm}^{3}$ and compression strength is $0.62-3.34 \mathrm{MPa}$ [16]; Muto et al. prepared an aluminium oxide thermal insulation material by using the hydrogel as the binding agent based on the house-of-cards structure as a template, and its thermal conductivity is $0.94 \mathrm{~W} / \mathrm{m} \mathrm{K}$ $\left(1600^{\circ} \mathrm{C}\right)$, while the compression strength is $1.7 \mathrm{MPa}$ [17].

The walnut shell powder itself is inexpensive and completely volatile after high temperature. It can be used as a burned pore former to prepare porous materials $[18,19]$. However, irregular pores will affect the mechanical and thermal properties of the material, which is due to the irrgular walnut shell powder left after burning. In this paper, the foaming method and the method of treating walnut shell powder with silica sol to produce two pores are combined to prepare magnesia insulation materials. The present study investigates the mechanical and thermal properties of magnesia insulation materials, and its properties were controlled by changing the amount of the walnut shell powder added. A magnesia porous material with low conductivity and high strength was developed to be used as an insulation material for the high-temperature kiln body. The pore microstructures and properties of the developed materials were thoroughly discussed, which not only improve the thermal barrier effect but also does not significantly reduce the strength to meet the operating requirements. It provides some theoretical basis and reference value for the future research and development and production of magnesia insulation materials.

\section{Materials and Methods}

2.1. Silica Sol-Impregnating Walnut Shell Powder (Sws). Weigh the silica sol (30\% solid content, Dezhou, China) and the walnut shell powder $\left(\mathrm{d}_{50} \leq 47.4 \mu \mathrm{m}\right.$, Sunshine Industry Co., Ltd., China) according to the mass ratio of $2: 1$, and then, mechanically stir for 15 minutes at a proper stir speed. Place the stirred mixture in a vacuum drying chamber for 3 times, and then, place it at $110^{\circ} \mathrm{C}$ for $24 \mathrm{~h}$, and then, crushing and grinding the dried walnut shell $(\mathrm{d} 50 \leq 63.1 \mu \mathrm{m})$.

The SEM photos of the walnut shell powder without treating with the silica sol (Figure 1(a)). It can be seen that the walnut shell powder has different shapes and uneven surface. The surface element scanning of untreated walnut shell powder (Figure 1(b)). The surface of walnut shell powder is mainly $\mathrm{C}$ and $\mathrm{O}$ elements.

Figure 2(a) is the SEM micrographs of the walnut shell powder after treatment with the silica sol. The surface element scanning of the walnut shell powder treated with the silica sol is shown in Figure 2(b). The walnut shell powder after treating by the silica sol is smoother on the morphology, and the surface is fully wrapped with silica particles. Through the analysis of surface scanning, the surface of the walnut shell powder is mainly $\mathrm{Si}$ and $\mathrm{O}$ at this time. It can be considered that the nanometer silica particles are well wrapped on the surface of the walnut shell powder. This is because the walnut shell powder is mainly composed of cellulose and lignocellulose, and its surface contains a large number of hydroxyl groups whose main elements are $\mathrm{C}$ and $\mathrm{O}$; the silica sol is a stable water-based suspension containing up to $30 \%$ of the nanometer-sized spherical amorphous silica particles (diameter is $8 \sim 15 \mathrm{~nm}$ ).

Figure 3 is the thermal analysis spectra of the walnut shell powder treated with the silica sol, and the heating processes of the walnut shell powder treated with the silica sol were characterized by the TG and DSC, conducive to analyze the reaction during the firing process.

The results in Figure 3 revealed that the main exothermic peaks and weightless peaks in the Sws were concentrated in the range of $90-400^{\circ} \mathrm{C}$. The exothermic peaks in this temperature range mainly were caused by the severe combustion of the walnut shell powder as an organics-rich substance, and the accompanying volatilization of gas and liquid resulted in the loss of weight. The exothermic peaks in $859^{\circ} \mathrm{C}$ mainly were caused by the crystalline transformation of silica. In this case, many voids would be generated inside the sample to form a porous structure, greatly conducive to the decrease of bulk density.

Structural diagram of the inner and outer surfaces of the silica sol is shown in Figure 4(a). When the pretreatment liquid treats the walnut shell powder, it is mechanically stirred and mixed and subjected to external force. The oxide sol particles $(5-100 \mathrm{~nm})$ have a smaller particle size and a larger specific surface area. It has strong activity. The hydroxyl $(-\mathrm{OH})$ on the surface of the walnut shell powder and the surface of the sol particles produces hydrogen bonds to combine the two. At the same time, the walnut shell powder has strong adsorption, and the oxide sol has strong adhesion. After dehydration, the sol particles adhere firmly to the surface of the walnut shell powder. The schematic diagram of the principle of treatment of the walnut shell powder by the treatment liquid is shown in Figure 4(b).

2.2. Preparation of Magnesia Porous Aggregate. The magnesia porous aggregate was obtained in this paper. The main raw material used was the high-purity magnesia powder (d50 $\leq 74 \mu \mathrm{m}, \mathrm{MgO}>96 \%$, Houying Co., Ltd., Haicheng, China), and potassium oleate (PO, CP, $\geq 79 \%$ ) was used as a foaming agent; $2500 \mathrm{~mL}$ foam was prepared by mixing $12 \mathrm{~g}$ PO with $1500 \mathrm{~mL}$ water with mechanical stirring for $15 \mathrm{~min}$ at a proper speed. Simultaneously take $3000 \mathrm{~g}$ of high-purity magnesia powder and add $500 \mathrm{ml}$ water to make magnesia slurry. The magnesia slurry and foam are mixed for 1 minute by adopting a mechanical stirring method at a proper rotating speed. After mixing, the mixture is moulded by casting. The sample is naturally cured with a mold for 24 hours. After demoulding to cure at $110^{\circ} \mathrm{C}$ for 24 hours, heat to $1550^{\circ} \mathrm{C}$ at $5^{\circ} \mathrm{C} / \mathrm{min}$ speed and keeping the temperature for 3 hours; Table 1 is the index of magnesia lightweight aggregate.

2.3. Preparation of Magnesia Thermal Insulation Materials and Test Method. Secondly, to prepare magnesia thermal insulation materials, the main raw materials used are magnesia porous aggregate, midrange magnesia powder 


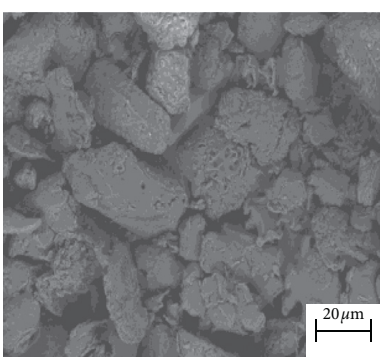

(a)

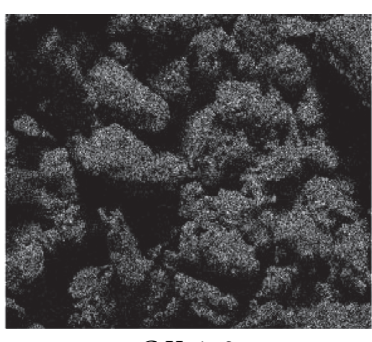

C Ka1_2

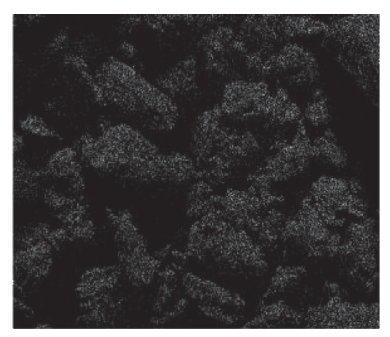

O Ka1

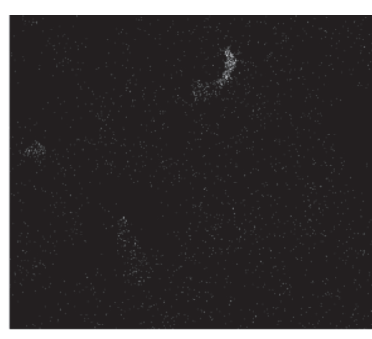

Si Kal

(b)

Figure 1: (a) SEM micrographs of the walnut shell powder without treating with the silica sol (500×). (b) Surface element analysis of untreated walnut shell powders.

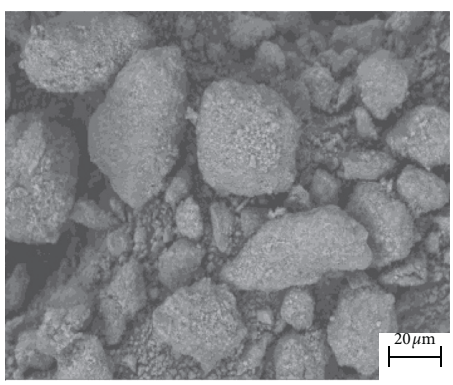

(a)

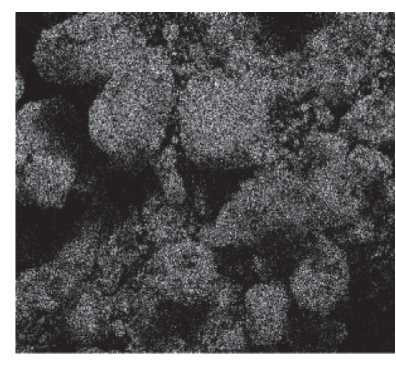

Si Ka1

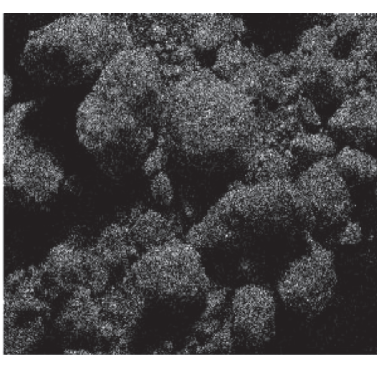

O Kal

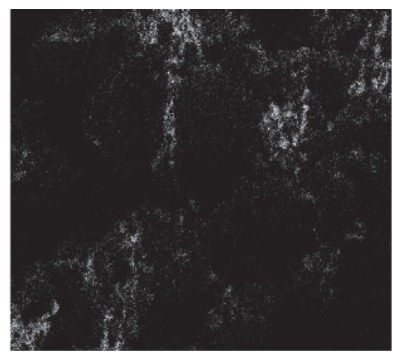

C Ka1_2

FIGURE 2: (a) SEM micrographs of the walnut shell powder treated with the silica sol (500×). (b) Surface element analysis of treated walnut shell powders with the silica sol.

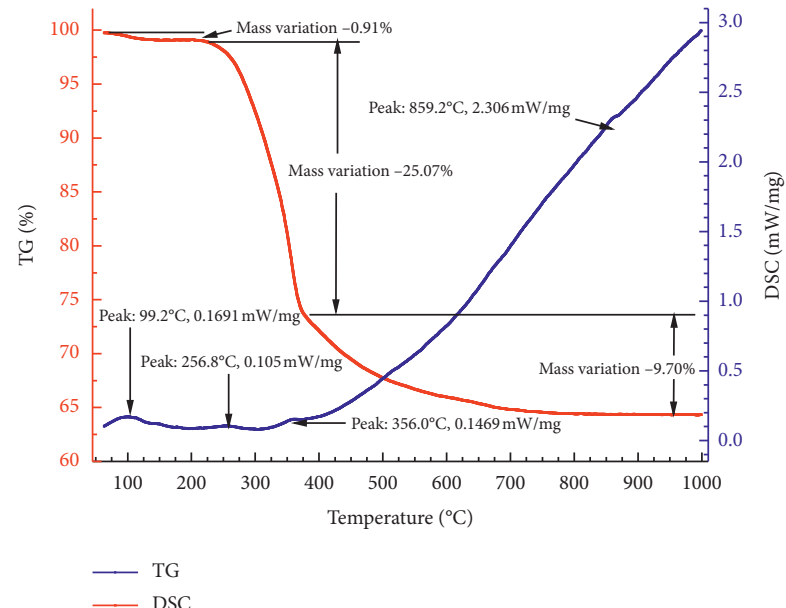

FIGURE 3: The thermal analysis spectra of the walnut shell powder treated with the silica sol.

(d50 $\leq 74 \mu \mathrm{m}$, Houying Co., Ltd., Haicheng, China), walnut shell powder $(\mathrm{d} 50 \leq 47.4 \mu \mathrm{m}$, Sunshine industry Co., Ltd., China), calcium aluminate cement (Lafarge Ruian Cement Co., Ltd., Beijing, China), silica powder, and silica sol (30\% solid content, Dezhou, China) as a surface modifier. Table 2 shows the chemical composition of the raw materials.

According to Table 3, the ingredients are put in the blender of cement mortar. The water amount is $15 \%$, the mixing time is $180 \mathrm{~s}$, and the stirred sample is placed in a mold with $160 \mathrm{~mm} \times 40 \mathrm{~mm} \times 40 \mathrm{~mm}$ and vibrated until the sample no longer generates bubbles, and it is cured with the mold at room temperature for 24 hours. After demoulding, it is placed in an oven and dried at $110^{\circ} \mathrm{C}$ for 24 hours and then sintered at $1300^{\circ} \mathrm{C}$ at $3^{\circ} \mathrm{C} / \mathrm{min}$ speed and kept warm for three hours.

The apparent porosity and bulk density of the burned sample are measured according to Archimede's principle of water displacement, and the total porosity and closed porosity of the material are calculated according to

$$
\begin{aligned}
& V_{\text {total }}=1-\frac{\rho_{\text {bulk }}}{\rho_{\text {true }}} \\
& V_{\text {close }}=V_{\text {total }}-V_{\text {open }},
\end{aligned}
$$

where $V_{\text {total }}$ is the total porosity, $V_{\text {open }}$ and $V_{\text {close }}$ are the apparent porosity and closed porosity, and $\rho_{\text {bulk }}$ and $\rho_{\text {true }}$ are the bulk density and true density, respectively. Observing and analyzing the microstructure of the sample using the scanning electron microscope (SEM, $\Sigma$ IGMA/ $\mathrm{HD}$, Jena, Germany), making $\varphi 180 \times 20 \mathrm{~mm}$ standard samples and measuring the thermal conductivity by using a thermal constants' apparatus (PBDR-02, Precondar, PR China), measuring the compression strength of the samples by the microcomputer-controlled electro-hydraulic servo pressure tester (YAW-100 KN, Jinli Experimental Technology Co., Ltd., China), and measuring the rate of linear change of the samples after sintering according to formula (3), three specimens were measured and averaged: 


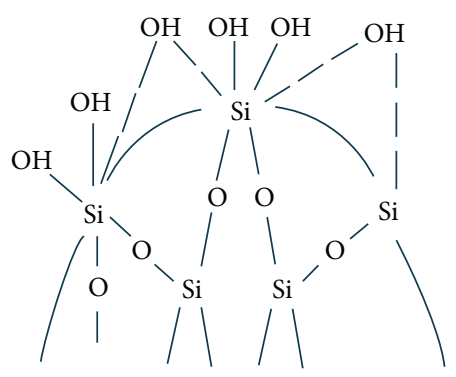

(a)

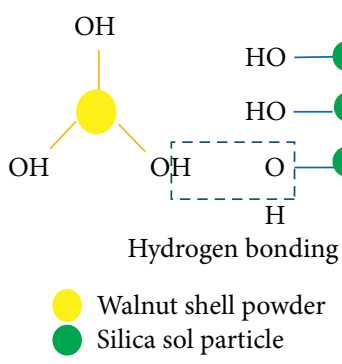

(b)

FIgURE 4: (a) Structural diagram of the inner and outer surfaces of the silica sol. (b) Schematic diagram of the surface principle of the silica sol-impregnated walnut shell powder.

TABle 1: The physical properties of sintered magnesia porous aggregates.

\begin{tabular}{lc}
\hline \multicolumn{2}{c}{ Raw materials } \\
Physical properties & Magnesia \\
\hline Bulk density $\left(\mathrm{g} / \mathrm{cm}^{3}\right)$ & 1.65 \\
Apparent porosity $(\%)$ & 43.6 \\
Numerical tube pressure $(\mathrm{MPa})$ & 18.6 \\
Pore size distribution $(\mu \mathrm{m})$ & $5-10$ \\
\hline
\end{tabular}

$$
\Delta L=\frac{L_{1}-L_{0}}{L_{0}} \times 100 \%
$$

where $\Delta L$ is the linear change rate after sintering, $L_{0}$ is the length of the specimen before sintering, and $L_{1}$ is the length of the specimen after sintering.where Ws10 represents the sample prepared by adding $10 \%$ walnut shell powder impregnated without the silica sol, Wsw10 represents the sample prepared by adding $10 \%$ walnut shell powder after impregnation with the silica sol, Wsw15 represents the sample prepared by adding $15 \%$ walnut shell powder impregnated with the silica sol, and Wsw20 represents the sample prepared by adding 20\% walnut shell powder impregnated with the silica sol.

\section{Results and Discussion}

3.1. The Performance at Normal Temperature of the Sample after Sintering. Table 4 shows the performance at normal temperature of the samples after sintering. As can be seen from the table, there is no significant change in the total porosity of Sws 10 and Ws10, but the apparent porosity is reduced by $10.1 \%$, while the closed porosity is increased by $44.6 \%$. This is because the walnut shell powder is surrounded by a large number of nano- $\mathrm{SiO}_{2}$ particles; as the temperature increases, the walnut shell powder is burned to leave holes. $\mathrm{SiO}_{2}$ particles have high activity at high temperatures which can promote sintering and gradually make the micropores smaller so that Sws10's linear shrinkage is also slightly higher than Sw10. With the increasing amount of the walnut shell powder treated by the silica sol, the bulk density and closed porosity of the sample gradually decreased, and the total porosity, apparent porosity, and line ratio gradually increased. Because the amount of the walnut shell powder inside the material matrix increased, it leaves a lot of pores after sintering so that through pores are formed between the pores, which leads to the closed porosity decreasing. The compression strength of Ws10 is $12 \mathrm{MPa}$, and the compression strength of Sws 10 is $18 \mathrm{MPa}$, which is an increase by $50 \%$ relatively. This is because the Sws10 sample has more closed pores inside the material than the Ws10 sample. When the material is subjected to external pressure, these closed pores can effectively decompose the surface pressure, thus avoiding the local stress concentration and then causing the material to be easily broken. With the increasing number of the walnut shell powder after dipping, the compression strength of the sample gradually decreases. When the walnut shell powder is added to $20 \%$, the compression strength of the sample is only $7 \mathrm{Mpa}$. Although the closed porosity of the Sws20 sample is relatively higher than Ws10 and because the total porosity is much higher than Ws10, there are a lot of pores inside the sample, so the compression strength is significantly lower than Ws10.

3.2. Thermal Conductivity of the Samples. Figure 5 shows the thermal conductivity of the four samples at different temperatures. It can be seen from the figure that, with the increase of the experimental temperature, the thermal conductivity of the four samples all show an increasing trend. This is because as the temperature increases, the propagation rate of heat flux is accelerated. When the heat flux passes through the holes in the material, the heat residence time inside that material is reduced, resulting in less heat being dissipated inside the materials, so the thermal conductivity is gradually increased. At $350^{\circ} \mathrm{C}$, the thermal conductivity of Ws10 and Sws 10 is not much different. The reason is that the walnut shell powder is added in the same amount (10\%), and the other main reason is that the walnut shell powder is not completely burned at this temperature, resulting in the incomplete formation of pores in the sample, so the difference between the two is not significant; but with the further improvement of temperature, the walnut shell powder is completely burned out, and the difference between the two is quite large. The main reason is that the nanosized silica particles will produce higher activity as the temperature increases to accelerate the movement speed of the surrounding boundary, thereby promoting sintering and making the macropores get miniaturized, and the pores gradually approach a circle, and meanwhile, when the heat passes through the circular pores, the heat flow propagation direction is deflected due to convection and radiation, and a part of the heat is stored in the pores so that the thermal conductivity can be reduced; another small part 
TABLE 2: Chemical compositions of the raw materials $(\omega / \%)$.

\begin{tabular}{|c|c|c|c|c|c|c|c|c|}
\hline Raw materials & $\mathrm{Al}_{2} \mathrm{O}_{3}$ & $\mathrm{SiO}_{2}$ & $\mathrm{CaO}$ & $\mathrm{MgO}$ & $\mathrm{Fe}_{2} \mathrm{O}_{3}$ & $\mathrm{~K}_{2} \mathrm{O}$ & $\mathrm{Na}_{2} \mathrm{O}$ & Il \\
\hline High-purity magnesia powder & 0.32 & 0.70 & 0.58 & 97.50 & 0.52 & & & 0.11 \\
\hline Porous magnesia aggregates & 0.34 & 0.71 & 0.60 & 96.80 & 0.55 & & & 0.23 \\
\hline Midrange magnesia powder & 0.15 & 1.51 & 2.20 & 94.22 & 0.92 & & & 0.2 \\
\hline Calcium aluminate cement & 69.8 & 0.40 & 29.40 & & & & & \\
\hline Walnut shell powder & 0.18 & 0.84 & 0.28 & 0.07 & & 0.24 & 0.04 & 98.28 \\
\hline Silica fume & 0.14 & 94.87 & 1.13 & 0.72 & & & 0.43 & 2.66 \\
\hline
\end{tabular}

TABLE 3: Samples' proportioning scheme.

\begin{tabular}{lccccc}
\hline \multicolumn{1}{c}{ Composition $(\omega / \%)$} & & Ws10 & Sws10 & Sws15 & Sws20 \\
\hline & $\begin{array}{c}8- \\
5 \mathrm{~mm}\end{array}$ & 10 & 10 & 10 & 10 \\
& $5-$ & 10 & 10 & 10 & 10 \\
& $3 \mathrm{~mm}$ & & & & \\
$\begin{array}{l}\text { Porous magnesia } \\
\text { aggregates }\end{array}$ & $\begin{array}{l}1 \mathrm{~mm} \\
1-\end{array}$ & 20 & 20 & 20 & 20 \\
& $0 \mathrm{~mm}$ & 15 & 15 & 15 & 15 \\
& & & & \\
Untreated walnut shell powder & 10 & & & \\
Treated walnut shell powder & & 10 & 15 & 20 \\
Calcium aluminate cement & 6 & 6 & 6 & 6 \\
Midrange magnesia powder & 27 & 27 & 22 & 17 \\
Silica fume & 2 & 2 & 2 & 2 \\
Sodium polyphosphate (additive) & 0.02 & 0.02 & 0.02 & 0.02 \\
\hline
\end{tabular}

TABLE 4: Normal temperature performance of the sintered samples.

\begin{tabular}{lcccc}
\hline Properties & Ws10 & Sws10 & Sws15 & Sws20 \\
\hline Total porosity (\%) & 64.45 & 64.09 & 68.17 & 70.17 \\
Apparent porosity (\%) & 53.17 & 47.78 & 52.54 & 56.83 \\
Close porosity (\%) & 11.28 & 16.31 & 15.63 & 13.34 \\
Bulk density (g/cm $\left.{ }^{3}\right)$ & 1.226 & 1.257 & 1.146 & 1.029 \\
Linear shrinkage (\%) & 1.8 & 2.2 & 3.7 & 4.8 \\
Compressive strength (MPa) & 12 & 18 & 13 & 7 \\
\hline
\end{tabular}

of it is that thermal conductivity of $\mathrm{SiO}_{2}$ is significantly lower than that of $\mathrm{MgO}$. As the amount of the walnut shell powder after impregnation increased, the thermal conductivity at the same temperature decreases. This is due to the increase in the number of pores in the material, which is equivalent to increasing the solid-gas contact area, which in turn increases the transmission routes of heat flux, making more heat loss inside the material so as to further reduce the thermal conductivity.

3.3. Microstructure of the Samples after Sintering. Figure 6 is a SEM photograph of the sample of Ws10, Sws10, Sws15, and Sws20. As can be seen from the figure of Ws10, the pores of the walnut shell powder left in the material matrix are different in size and are not evenly distributed. Due to the mutual adhesion phenomenon of the walnut shell powder, it results in more pores with different shapes after burning, that is, more through holes. This type of pores is easy to produce stress concentration when subjected to the external stress effect, which leads to a decrease in the mechanical properties of the material. Therefore, the compression strength of Ws10 is $12 \mathrm{MPa}$, but the difference can

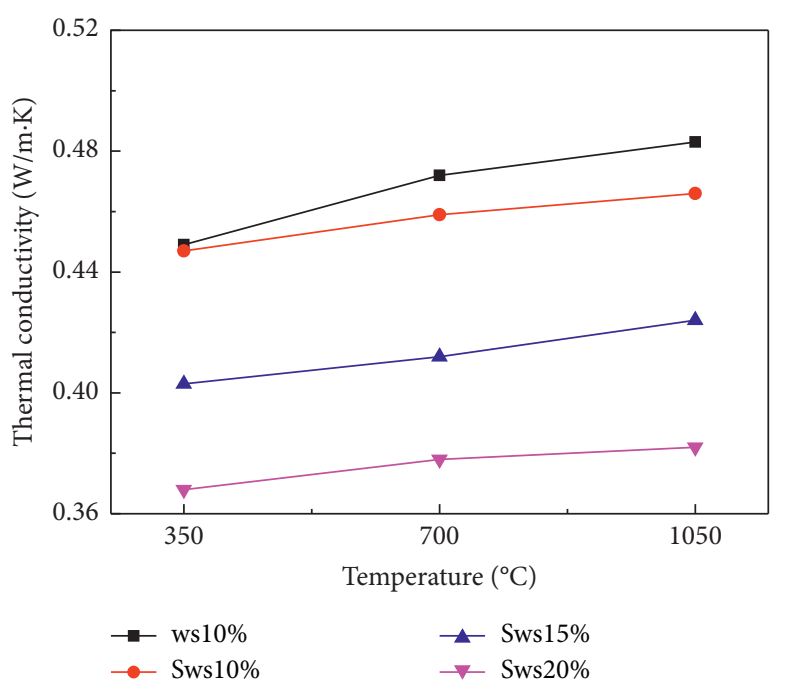

Figure 5: Thermal conductivity of the four samples at different temperatures.

be seen from the figure of Sws 10 that the shape of most of the pores in the matrix is the circle, and the pores are distributed regularly, and there is basically no hole-through between them. When subjected to external forces, the circular pores can effectively decompose the stress and avoid the phenomenon of local stress concentration. Therefore, the compression strength of Sws10 has reached $18 \mathrm{MPa}$, which will benefit from the high closed porosity inside the sample. With the continuous increase of the walnut shell powder treated by the silica sol, it can be seen from figures of Sws 15 and Sws20 that the holes gradually increase. Although the pores left by burning the walnut shell powder can still maintain a circular shape, due to the increased amount of the walnut shell powder, the probability of mutual contact between the shell powders increases, which leads to the intensification of the phenomenon of through pores so as to further affect the compression strength of the sample. From the figure of Sws20, it can also be seen that there are thick and linear through-holes at the juncture between the aggregate and the matrix. This is because a large amount of the walnut shell powder is wrapped around the aggregate during the pouring process, and the through-holes left after burning, due to the poor binding between the aggregate and the matrix, will also affect the mechanical properties of the material after sintering.

Figure 7 is the microstructure of Sws10 fracture and section. It can be seen that the magnesia-aluminate spinels with an octahedral structure around the pore diameter are 

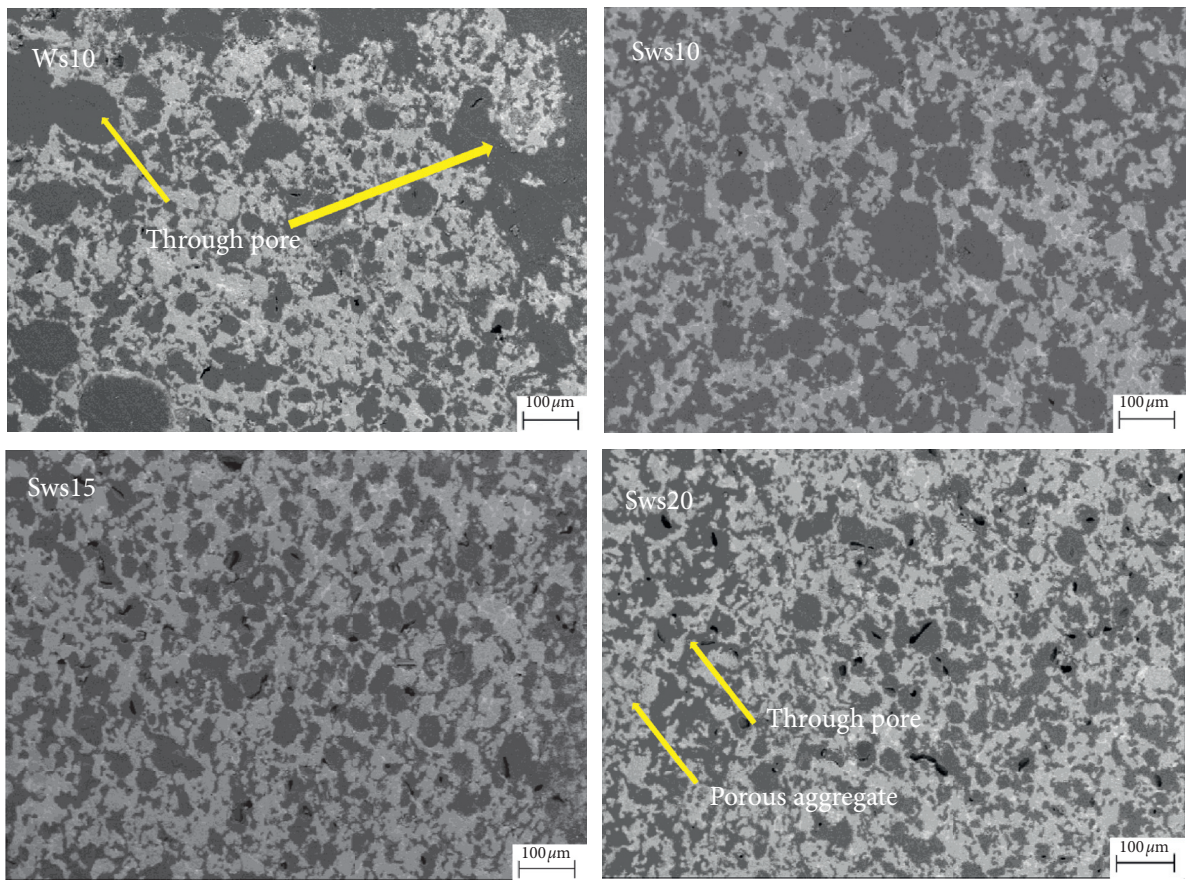

Figure 6: SEM micrographs of sintered specimens (50×).

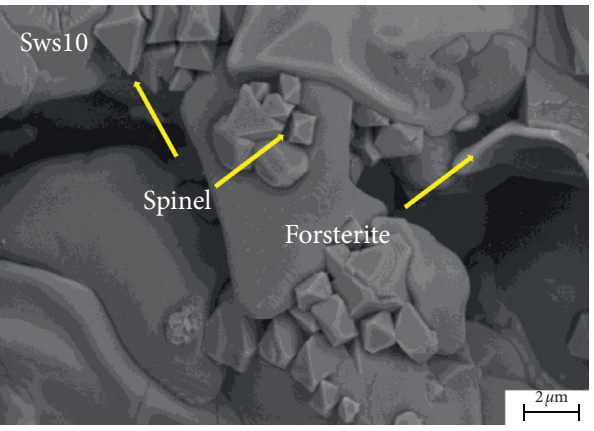

FIGURE 7: SEM picture of inner hole morphology (3000×).

caused by the reaction between high aluminium oxide in calcium aluminate cement and the magnesia oxide in the matrix at high temperature. The chemical reaction formula is shown in formula (4); secondly, the formation of forsterite with the stratified structure can be clearly seen on the inner wall of the aperture. Because the nanosized silica particles fully wrap the walnut shell powder and as the temperature gradually rises, the walnut shell powder is burned, and the surrounding nanosized silica particles produce ultrahigh activity, reacting with the surrounding magnesia oxide particles to form forsterites, and the chemical reaction formula is shown in formula (5). This stratified structure is equivalent to a layer of coat for the pores. Because the nano particles have the effect of promoting sintering, when the pores have this layer of coat, they can maintain their circular shape without damage, and the pore size will gradually shrink. When the material subjected to external stress and then transmitted to the hole, the forsterite with the sheet structure around the pore can also play a good role in resisting external forces:

$$
\begin{aligned}
& \mathrm{Mgo}+\mathrm{Al}_{2} \mathrm{O}_{3}{ }^{\circledR} \mathrm{MgAl}_{2} \mathrm{O}_{4}, \\
& 2 \mathrm{MgO}+\mathrm{SiO}_{2}{ }^{\circledR} \mathrm{Mg}_{2} \mathrm{SiO}_{4} .
\end{aligned}
$$

\section{Conclusions}

The innovative method of preparing new magnesia lightweight materials through the use of home-made magnesia lightweight aggregates and, at the same time, through the use of the silica sol-impregnating walnut shell powder as a pore former has been successfully studied. The samples prepared by the impregnated pore former can show more superior mechanical and thermal properties, and the pore shape, size, and distribution inside the sample are effectively improved.

(1) By adding $10 \%$ Sws, the bulk density of the sample after burning is $1.257 \mathrm{~g} / \mathrm{cm}^{3}$, the closed porosity is $16.31 \%$, the compression strength is $18 \mathrm{MPa}$, and the thermal conductivity is $0.466 \mathrm{~W} / \mathrm{mK}\left(1050^{\circ} \mathrm{C}\right)$.

(2) When the addition amount of the walnut shell powder treated by the silica sol is $20 \%$, the bulk density of the material after burning decreases to $1.029 \mathrm{~g} / \mathrm{cm}^{3}$, and the thermal conductivity is $0.382 \mathrm{~W} / \mathrm{mK}\left(1050^{\circ} \mathrm{C}\right)$.

(3) Through SEM analysis, when using the silica solimpregnating walnut shell powder as the pore former, the surface structure of the walnut shell powder is effectively improved. After burning, the pores left inside the sample are more evenly distributed, and the pore size is shrunk. The pore type has been effectively improved, and the through pores have been significantly reduced, which is also the main reason 
for the improvement of the mechanical and thermal properties of the material.

\section{Data Availability}

The data used to support the findings of this study are available from the corresponding author upon request.

\section{Conflicts of Interest}

The authors declare that they have no conflicts of interest.

\section{Acknowledgments}

This work was financially supported by National Key R \& D Program of China (no.2017YFB0310701).

\section{References}

[1] M. C. Oliveira, M. Iten, P. L. Cruz et al., Review on Energy Efficiency Progresses, Technologies and Strategies in the Ceramic Sector Focusing on Waste Heat Recovery, 2020.

[2] Q. Wan, H. Yin, Y. Tang et al., "“Effect of carbon sources on the properties of lightweight corundum-spinel refractory with density gradient," International Journal of Applied Ceramic Technology, vol. 17, no. 2, 2020.

[3] J. Qiao and Y. Wen, "Preparation and characterization of magnesium aluminate $(\mathrm{MgAl} 2 \mathrm{O} 4)$ spinel ceramic foams via direct foam-gelcasting," Ceramics International, vol. 46, no. 1 , pp. 678-684, 2020.

[4] Y. Luo, H. Gu, M. Zhang, A. Huang, and P. Yan, "Research on thermal shock resistance of porous refractory material by strain-life fatigue approach," Ceramics International, vol. 46, no. 10, pp. 14884-14893, 2020.

[5] E. S. Kang, Y. W. Kim, and W. H. Nam, "Multiple thermal resistance induced extremely low thermal conductivity in porous $\mathrm{SiC}-\mathrm{SiO} 2$ ceramics with hierarchical porosity," Journal of the European Ceramic Society, vol. 41, no. 2, 2020.

[6] M. L. Sandoval, L. Ramajo, and M. A. Camerucci, "Cellular mullite materials processed by direct foaming and protein casting," Journal of the European Ceramic Society, vol. 39, no. 7, pp. 2472-2483, 2019.

[7] J. Liu, Y. Li, S. Li, N. Xu, R. Xiang, and Q. Wang, "Microporosity and properties of light-weight insulation refractories based on calcined flint clay," Transactions of the Indian Ceramic Society, vol. 78, no. 1, pp. 7-12, 2019.

[8] M. Bengis and E. Yilmaz, "Gelcasting of alumina and zirconia using chitosan gels," Ceramics. International, vol. 28, no. 24, pp. 431-438, 2002.

[9] Z. Du, D. Yao, Y. Xia et al., "Tailoring the microstructure of high porosity Si3N4foams by direct foaming with mixed surfactants," Journal of the American Ceramic Society, vol. 102, no. 11, pp. 6827-6836, 2019.

[10] Y. Zou, H. Gu, A. Huang, L. Fu, and G. Li, "Fabrication and analysis of lightweight magnesia based aggregates containing nano-sized intracrystalline pores," Materials \& Design, vol. 186, 2020.

[11] G. Wu, W. Yan, S. Schafföner et al., "A comparative study on the microstructures and mechanical properties of a dense and a lightweight magnesia refractories," Journal of Alloys and Compounds, vol. 796, pp. 131-137, 2019.

[12] D. O. Obada, D. Dodoo-Arhin, M. Dauda, F. O. Anafi, A. S. Ahmed, and O. A. Ajayi, "Physico-mechanical and gas permeability characteristics of kaolin based ceramic membranes prepared with a new pore-forming agent," Applied Clay Science, vol. 150, pp. 175-183, 2017.

[13] K. Mohanta, A. Kumar, O. Parkash, and D. Kumar, "Low cost porous alumina with tailored microstructure and thermal conductivity prepared using rice husk and sucrose," Journal of the American Ceramic Society, vol. 97, no. 6, pp. 1708-1719, 2014.

[14] J. Liu, B. Ren, T. Zhu et al., "Enhanced mechanical properties and decreased thermal conductivity of porous alumina ceramics by optimizing pore structure," Ceramics International, vol. 44, no. 11, pp. 13240-13246, 2018.

[15] Z. Wei, S. Li, Y. Li, X. Li, R. Xiang, and N. Xu, "Porous alumina ceramics with enhanced mechanical and thermal insulation properties based on sol-treated rice husk," Ceramics International, vol. 44, no. 18, pp. 22616-22621, 2018.

[16] M. Yang, X. Luo, J. Yi, M. Yu, and X. Zhang, "A novel way to fabricate fibrous mullite ceramic using sol-gel vacuum impregnation," Ceramics International, vol. 44, no. 11, pp. 12664-12669, 2018.

[17] D. Muto, S. Hashimoto, H. Kondo, Y. Daiko, S. Honda, and Y. Iwamoto, "Fabrication of highly isotropic porous alumina refractory clinkers consisting of platelets using a gelatin-sol," Journal of Asian Ceramic Societies, vol. 8, no. 2, pp. 265-276, 2020.

[18] Y. Li, M. Yue, J. Ye, T. Xu, and Y. Liu, "Walnut shell powder can limit acid mine drainage formation by shaping the bacterial community structure," Current Microbiology, vol. 76, no. 10, pp. 1199-1206, 2019.

[19] A. Zamani, A. Poursattar Marjani, and M. Abedi Mehmandar, "Synthesis of high surface area magnesia by using walnut shell as a template," Green Processing and Synthesis, vol. 8, no. 1, pp. 199-206, 2018. 